\title{
Lessons From India In Organizational Innovation: A Tale Of Two Heart Hospitals
}

How organizational innovation can reform health care, and (more important) why it hasn't.

\section{by Barak D. Richman, Krishna Udayakumar, Will Mitchell, and Kevin A. Schulman}

ABSTRACT: Recent discussions in health reform circles have pinned great hopes on the prospect of innovation as the solution to the high-cost, inadequate-quality U.S. health system. But U.S. health care institutions-insurers, providers, and specialists-have ceded leadership in innovation to Indian hospitals such as Care Hospital in Hyderabad and the Fortis Hospitals around New Delhi, which have U.S.-trained doctors and can perform open heart surgery for $\$ 6,000$ (compared to $\$ 100,000$ in the United States). The Indian success is a window into America's stalemate with inflating costs and stagnant innovation. [Health Affairs 27, no. 5 (2008): 1260-1270; 10.1377/hlthaff.27.5.1260]

Sign In the fortis Delhi encapsulates the starkest difference between Indian hospi-
in Nals and their U.S. counterparts: to celebrate "Heart Month," Fortis announced a "10\% discount on PTCA (Angioplasty) \& CABG (Bypass Surgery)."1

The recent rise of India's middle class has meant the emergence of several million new health care consumers looking to opt out of India's free public hospitals and instead pay for private health care services. Accordingly, India has seen a rise of private hospitals catering to these consumers in the emerging cash-pay market for hospital care. Care Hospital facilities around Hyderabad, the network of Fortis Hospitals around New Delhi, and many other private hospitals are targeting the 300 million Indians who count themselves among the nation's middle class.

India presents a stark contrast to the United States. The nation's entire health sector is estimated to be $\$ 20$ billion in size (compared to $\$ 2.3$ trillion in the United States), with more than 80 percent coming from private resources. Fewer than 14

Barak Richman (barak.richman@duke.edu) is a professor of law at the Duke University School of Law in Durham, North Carolina. Krishna Udayakumar is an assistant professor of medicine at Duke University Medical Center. Will Mitchell is the J. Rex Fuqua Professor of International Management at Duke University's Fuqua School of Business. Kevin Schulman is a professor of medicine at the Duke University School of Medicine and a professor of business administration at Duke University's Fuqua School of Business. 
percent of Indians purchase health insurance, and with a national per capita gross domestic product (GDP) of US\$820, Indian hospitals understand that their services have to meet the middle-class family budget, even for major surgery. Thus, Fortis Hospitals charges \$6,000 for open-heart surgery. Care Hospital charges slightly less. Narayana Hrudayalaya (NH) Heart Hospital in Bangalore, a charitable hospital, charges just over $\$ 2,000 .^{2}$ Meanwhile, open-heart surgery at a U.S. research hospital typically bills at more than $\$ 100,000$. Despite the price difference, private Indian hospitals provide world-class service: doctors with training comparable to that of U.S. physicians (many with medical training in the United States), the latest technology and equipment, and infection and mortality rates that compare to those of U.S. hospitals.

Why is there such a difference in costs for services with similar outcomes? To be sure, lower labor costs in India play an important role. But much of the Indian success can be attributed to experimenting with, developing, and constantly improving innovative organizational structures to provide care. At the extreme, these structures offer textbook examples of organizational innovation, and they suggest what might be possible if the U.S. health care market were permitted to experiment with new organizational forms.

\section{Organizational Innovation And The Health Sector}

Recent discussions in health reform circles have pinned great hopes on the prospect of innovation as the solution to the high-cost, inadequate-quality U.S. health system. Clay Christensen, using the template from his popular The Innovator's Dilemma, has helped spark the optimism by encouraging "disruptive innovation" to transform the U.S. health sector. ${ }^{3}$ This model of change has entrants challenging industry leaders with low-cost technologies that, over time, achieve similar or better performance than the existing standard. As these entrants supplant incumbents, they force market participants-and often the market structure itself-to undergo organizational change, and this transformation creates value for both innovators and consumers.

Accordingly, much of the literature on organizational innovation looks to entrants, rather than incumbents, to drive innovation and to catalyze incumbent firms to respond. ${ }^{4}$ Most innovation-intensive industries thus regularly undergo major changes, including wholesale cycling of industry leadership. ${ }^{5}$ But the U.S. health sector has been strikingly ossified, with the same industry leaders (academic hospitals and university medical centers) that led a generation or more ago continuing to hold leadership status today. Disruptive innovation is fueled by entrants, yet the U.S. health care market has managed to either exclude or cripple realistic challenges posed by newcomers with innovative organizational forms.

In this paper we explore the organizational innovations that have emerged in Indian hospitals out of India's competitive and more open marketplace, and we discuss features of the U.S. regulatory environment that impede similar innovation. 


\section{Indian Innovations}

India is a land of stark contrasts, with a heterogeneous health care delivery system and 1.2 billion people who exhibit vast health disparities. For example, India's lowest wealth quintile has a mortality rate for children under age five that is three times that of the highest wealth quintile, and a measles immunization rate of less than half. ${ }^{6}$ Similar disparities exist in the quality of health care offered by India's hospitals. While India's public hospitals have struggled, the private health sector has seen an explosion of interest concurrent with the country's economic growth. Two-thirds of Indian households rely on private medical care, a preference that appears to cut across classes, and even rural and paramedic care are dominated by the private sector. ${ }^{7}$ Although India's elite institutions now rival top Western hospitals in quality (and have attracted a sizable number of Western patients, while garnering much media attention), these private systems were designed for and are geared to the health needs of India's middle class - and thus target the Indian middle-class budget-with the public sector serving as a safety-net provider. ${ }^{8}$ This is not a system designed for equity, but it is one in which world-class capacity has developed in a short period in the private sector.

To explore how India's health-sector innovations have achieved such high quality, high volume, and affordability, we focus on its heart hospitals and other private hospitals that specialize in open-heart surgery and angioplasty. Heart disease is one of the most common illnesses in India, with approximately 2.4 million people needing heart surgery every year, and heart hospitals such as Care Hospital in Hyderabad and the Fortis Hospitals in New Delhi now perform large volumes of procedures at high success rates. ${ }^{9}$ We examined these hospitals as leaders in this growth, seeking to extract lessons both for U.S. hospitals and for policymakers. These hospitals illustrate how Indian health care providers have focused on a particular high-demand service, built a large capacity to provide that service at an affordable cost, and developed assorted organizational innovations to support its business model.

- Management structure of hospitals. Many of the leading innovative health care organizations in India are led by dynamic physician-executives. For example, across its more than ten hospitals, Care Hospital develops physician leadership at each facility with a "servant leadership" model that empowers physician-led initiatives. Likewise, physicians and senior administrators at Fortis view themselves as a collaborative leadership partnership. This model enables "owner-operator" innovations that are agile and patient-focused.

Also within hospital management teams are managers with experience in India's burgeoning hotel industry. The application of management routines and capabilities from the hotel industry helps Fortis and other hospitals manage patient care in the context of customers' experiences and patients' expectations. This reflects a much more focused customer/patient approach than that at many U.S. 
counterpart hospitals.

- Price discrimination by service providers. In a market where hospitals compete on both price and quality, many Indian health care delivery organizations have adopted the practice of price discrimination (differential pricing) to target multiple segments of the ever-changing Indian population. Care, for example, has deployed a "multi-tariff" system for the provision of standard services, charging higher fees for comparable services to higher-income segments of the patient base. This tiered pricing model is one of the cornerstones of the Care business model, allowing the organization to provide services either with minimal margins or below full cost (but above variable cost) to approximately 75 percent of its patients. Other private hospitals similarly offer more luxurious services for higher prices. There is an explicit focus on limiting fixed costs to achieve budgetary goals while maintaining quality, so price discrimination occurs primarily on capital costs and less on technology and services. Patients can pay more to enjoy more-elegant rooms, but the technologies used for procedures are the same for all patients.

Another aspect of price discrimination is hospitals' explicit targeting of patients from different income sectors. Fortis targets the upper-middle-class population with its price points for services, while Care targets the lower middle class. Both can make valid claims of high-quality care, so the differences in pricing strategies play out largely in areas not directly related to clinical care. This model is reflected in the capital expenditure and facilities strategies of Fortis and Care: Fortis locates facilities in higher-income neighborhoods across urban areas, while Care's strategy includes locating facilities on the periphery of urban areas, in cheaper real estate markets and closer to its targeted lower-income patients.

These cross-subsidies via price discrimination also contribute greatly to the hospitals' innovation. They enable the hospitals to maintain high volume and low overhead costs and to continually focus on improvement. The sliding-scale pricing is important because it attracts large numbers of limited-income patients, maintains a large volume of consumers, and supports the routines that continually seek to improve quality and efficiency.

Quality in a fixed-price model. Competitive pressures are forcing many hospitals in India to offer services with capitated pricing. In a market largely not penetrated by insurance coverage, patients as payers are better able to "shop" for medical procedures by comparing prices in this model, which also shifts financial risk to the service providers.

Within these emerging fixed pricing schemes, Indian hospitals have managed to build capital, labor, and systems investment strategies to maximize quality of care with pricing constraints. Care has described a model of "reverse engineering" under which the organization starts from the targeted market price for a service and derives an appropriate cost structure for providing that service with appropriate quality. This mechanism facilitates continued evaluation of the cost drivers for services and provides the market pressure for development of new, innovative 
approaches to care delivery.

The high-quality, low-cost combination requires supporting organizational innovation. For instance, a component of Care's labor strategy for achieving quality within fixed pricing is the implementation of "de-skilling," in which Care repackages certain functions of positions that less-trained or lower-level personnel can perform. Fortis also pursued de-skilling and, for example, developed a program to train unemployed women from the local community to serve as dialysis technicians. De-skilling not only cuts costs by substituting lower-cost labor when possible, but it also addresses local labor shortages in skilled and trained personnel.

Drive for efficiency in supply and delivery chains. In a competitive market with high fixed costs, the drive for efficiency demands increased production volumes. Many Indian hospitals have responded to these demands by reengineering their service delivery models to maximize use of capital equipment. An example is continuous use of radiology equipment at Care, with outpatient studies done by appointment during the day and inpatient radiology studies done overnight, avoiding periods of downtime for capital equipment. NH Heart Hospital, meanwhile, has developed an efficient turnover of operating rooms and cardiac catheterization facilities, allowing for much higher volumes of services with only moderate investment in capital equipment.

The emphasis on efficiency has also influenced supply-chain management. There is intense scrutiny of materials management, with efforts to reduce costs of supplies without compromising quality. For example, Care actively evaluates noncritical equipment, such as monitors, from lower-price sources such as China, carrying out head-to-head, months-long comparisons with more costly global brands. Care actively deploys these lower-cost technologies across all of its facilities if they meet internal quality standards.

The relentless drive for efficiency and lower cost of care has led Care to develop and commercialize technologies as an offshoot of its health care delivery business. Relisys, part of the Care Group (which includes Care Hospitals and Care Foundation), is focused on commercialization of indigenous technology and equipment. This commercialization, including self-manufacturing of medical equipment, has become a critical component of Care's strategy for cost reduction..$^{10}$ Relisys operates its own manufacturing plant near Hyderabad that meets international good manufacturing practice (GMP) standards, with capacity to manufacture 200,000 stents and 120,000 diagnostic catheters annually. The ability of Indian firms to self-manufacture medical equipment has played a key role in facilitating innovation and cost reduction.

Relisys began by developing and manufacturing routine equipment, such as intravenous lines, central venous catheters, and cardiac catheterization guidewires, allowing Care to minimize the costs to procure these products and thus further cater to its target lower-middle-class patient population. Over time, Relisys has improved internal research and development (R\&D) capabilities to focus on 
higher-value technology, such as drug-eluting coronary stents. By starkly reducing the costs for stents, the major driver of pricing for percutaneous coronary intervention in India, these innovations are expanding the market for cardiac services for local lower-income populations.

Further organizational innovations that improve efficiency and increase access to care include investing in information technology (IT) solutions for distance care, such as telemedicine. Health care delivery models use trained workers from the local community to gather primary data and relay this information to the appropriate medical personnel, who may be hundreds or thousands of miles away. Diagnostic services provided under this model include computed tomographic (CT) scanning and echocardiography with real-time tele-interpretation. Not only does this practice reduce the costs of providing care, it also eliminates the financial burden for rural Indians of traveling to urban areas for medical care.

Engineering perspective on service management. Many practices derived from the field of engineering, including continuous measurement and comparison of data across facilities, are helping Indian companies provide better services. Some organizations, such as Care and Fortis, employ engineers to drive data management systems within their facilities. Real-time monitoring of data allows many Indian hospitals to track and benchmark costs of care by patient, by provider, by service, and by other pertinent parameters. Data regarding variations from expected costs of care are captured and evaluated to regularly refine their models of care delivery. When he first started at Fortis, Daljit Singh, president of strategy and organizational development and a chemical engineer by training, noticed that there was substantial variation in clinical practice at Fortis. He had medical charts abstracted so that he could understand the variation and then worked with the physicians to review the data and reduce the variation in care.

The telemedicine technologies described above also support service management. Care, for instance, uses its telemedicine systems for daily video conferences among all facilities. This practice allows the hospitals to integrate data communication across facilities and analyze deviations from internal benchmarks.

This engineering focus enables Indian hospitals to continuously learn from and improve their clinical services. Unlike the ubiquitous cost-benefit analyses that pervade many U.S. hospitals, the orientation of the engineer maintains a clinical focus on patient services while continuously evaluating quality. ${ }^{11}$

- Competing on quality, paying for mistakes. Because Indian hospitals compete on both quality and price, hospital managers have instituted quality assurance and improvement as integral to the business models. In a low-price setting, these hospitals must maintain high-quality services to minimize adverse events, which generally raise the costs of care. Acceptance of financial risk by hospitals within capitated models for care delivery in India has added another driver for quality and efficiency. This concept was aptly summarized by N. Krishna Reddy of Care Hospital, who stated that in this business model, "we can't afford to have complications." 


\section{Pursuing Indian-Style Innovation In The United States}

The U.S. health care system has obviously evolved very differently from the Indian hospitals we describe. Nonetheless, Indian achievements in attaining similar outcomes at dramatically lower costs invite the question of whether U.S. hospitals and health policymakers can learn from India's remarkable experimentation, entrepreneurialism, and technological progress.

Growth of U.S. specialty hospitals. Lessons in business strategy and regulatory policy might be most applicable if we compare India's growth in heart hospitals to a similar explosion of interest in U.S. specialty hospitals. ${ }^{12}$ The growth of U.S. specialty hospitals was motivated by promises to deliver health care of higher quality and at lower costs than general hospitals by specializing in specific offerings and capabilities, producing a higher volume of services and reducing overhead costs. ${ }^{13}$

The achievements of these market entrants, however, were mixed, and examining their impact offers a revealing window into competition in the U.S. health sector. First, the quality of care at specialty hospitals is in dispute. Some early indications that specialty hospitals had higher margins and lower costs were countered by charges that the hospitals "cream-skimmed" patients who requested the most lucrative procedures and presented the fewest complications. ${ }^{14}$ More significant, there were concerns that instead of delivering on the promise of efficiency, these hospitals achieved financial success merely by exploiting current hospital reimbursement policies. Since payment in the United States (whether by the government or a private insurer) is not based on quality or clinical outcomes, part of the specialty hospitals' business models might have been careful patient selection. ${ }^{15}$ The most recent and detailed analysis by the Medicare Payment Advisory Commission (MedPAC) and the U.S. Department of Health and Human Services (HHS) in 2006 concluded that there is little evidence that an efficiency-based business model is the one that actually developed. ${ }^{16}$

In sum, U.S. specialty hospitals seem to have evolved to seize financial opportunities offered by an imperfectly regulated payment system, rather than to exploit an opportunity for high-quality, lower-cost services. Whereas new heart hospitals in India's largely unregulated health services market have to compete on the basis of price and quality, specialty hospitals in the United States do not appear to compete on either basis. It is instructive to examine features of the U.S. regulatory environment that have discouraged value-based competition and impeded the organizational innovation that is now shaping the Indian market.

Medicare and insurance payment policies. U.S. reliance on Medicare reimbursement played an important role in the strategic development of specialty hospitals. The diagnosis-related group (DRG) payment system forces innovators to find an appropriate rate from existing DRGs, instead of receiving a payment appropriate for the service rendered and the costs associated with it.

Reliance on DRG reimbursement can have several consequences. First, the 
DRG system can restrain price competition by sustaining overly compensated but inefficient incumbents while diluting the cost advantages brought by innovations. Second, the lengthy and cumbersome procedure to establish new DRGs can discourage innovators with new business from entry because they will not be matched with appropriate reimbursements in their early years. For example, MedCath, a U.S.-based owner and operator of cardiac hospitals, waited ten years before receiving a reimbursement scheme that was appropriate for its services. Finally, hospitals cannot price flexibly, as Indian private hospitals do, and thus do not have incentives to find sustainable price points that are appropriate for different market segments. Orchestrating cross-subsidies or flexible pricing could be important for entrants trying to gain traction in a new market.

Moreover, there is no means for innovative providers to negotiate with the Centers for Medicare and Medicaid Services (CMS) to secure appropriate reimbursement rates for novel procedures or new delivery models. Thus, even if the owners of specialty hospitals want their organizations to evolve into a truly value-creating business model, the means for them to do so has been lacking. ${ }^{17}$

Private insurance reimbursement can also impede price competition. Since insurers have difficulty meaningfully confronting providers that have market power, insurance networks are often forced to include all of the clustered services that dominant hospital chains offer, including all tertiary services that would normally be targets by more-efficient entrants. ${ }^{18}$ Consequently, insurers do little to stimulate price competition or encourage entry in hospital submarkets where specialty hospitals could increase value. ${ }^{19}$

The pervasiveness of insurance might also, although less directly, impede highquality care by requiring much administrative attention. In U.S. hospitals, administrators responsible for arranging insurance reimbursements are present throughout the patient's hospital stay. In Indian hospitals, however, the parallel support personnel come out of the nation's hospitality industry and are dedicated to improving the patient's comfort and satisfaction.

- The Stark Amendment. Section 1877 of the Social Security Act, first passed in 1989, prohibits physicians from referring Medicare beneficiaries for certain health services to an entity with which the physician or a member of the physician's immediate family has a financial relationship. This legislation, known as the Stark Amendment, designed to combat physician self-referral and Medicare abuse, was expanded in 1993 and 1994 to cover a broader spectrum of health services, and the Medicare Prescription Drug, Improvement, and Modernization Act (MMA) of 2003 specifically applied the prohibition to physicians' ownership of and investment interests in specialty hospitals. Although intended to address the challenge of physician oversight, these rules have contributed to a stifling of the development of physician-owned hospitals. They have thus deterred physicians' investment in new facilities and discouraged their involvement in corporate strategy, both of which were beneficial in the Indian heart hospitals. 
Opposition to self-referral is also expressed by administrators of general hospitals, because it channels their patients toward specialty hospitals. Political pressure from hospital lobbyists (in addition to concerns over the efficiency of specialty hospitals and distrust of self-referral) led to a moratorium on payments to specialty hospitals in $2005 .{ }^{20}$ Congress's decision to block payment to market entrants largely quieted market competition-a windfall few U.S. incumbents would dare request but a service that is not too unusual for health care providers - and perhaps hurt a reasonable chance at meaningful innovation in hospital services. ${ }^{21}$

- Tort standards. U.S. negligence law requires that providers offer care that meets a community standard.2. Because innovations, by definition, are deviations from the community standard, they are vulnerable to being labeled negligent and becoming the target of a legal suit. This vulnerability exposes innovators to liability that does not threaten incumbent providers, who abide strictly by the status quo. Moreover, although certain doctrines in negligence law have been known to hold providers liable even when courts deem the community standard to be too low, no such doctrine allows providers to escape liability by arguing that a widely held community standard is too high. ${ }^{23}$

Thus, tort law can lock in expensive and conventional practices and expose potential disruptive innovators to liability. Note that malpractice law applies in medical settings differently from the way product liability law applies in the industries studied by Christensen. In the Christensen model, innovations spawn low-cost alternatives to incumbent products that are, initially, considered to be of inferior quality. Medical malpractice law, however, penalizes innovation that cannot match the quality of the current paradigm, even if the innovation offers cost advantages and even if the innovation's quality improves over time. Initial offerings that do not meet a community standard will be deemed malpractice.

Indian accomplishments reveal how tort standards can impede sorely needed innovation in the health sector. Many of the Indian successes have come out of experimentation, where Indian doctors and corporate strategists tried out new routines and where engineers continuously proposed possible improvements and measured the quality-cost trade-offs for each trial. If U.S. tort law took costs into account more explicitly, or were more tolerant of variations in approaches to highquality care, perhaps the law would be less discouraging of the experimentation that is required to innovate.

\section{Learning From India: Same-Quality Outcomes At A Tenth Of The Cost}

Once again, health care reform is atop the U.S. political agenda, along with the oft-stated demands for cost reduction and quality improvement. What is striking from this one study of a select group of Indian hospitals is that there are alternatives in health care delivery that can achieve outcomes of the same quality at a tenth of the cost. U.S. hospitals could learn from some of these successes, and 
policymakers should reexamine barriers to organizational innovation that prevent U.S. entrepreneurs from moving in a similar direction.

Although most innovation-intensive industries have enjoyed a history of producing new generations of industry leaders, offering dramatic improvements in both capability and affordability, the U.S. health sector has not. Recent events in India suggest that the U.S. regulatory environment, not just the nature of health care itself, plays an important role. Indian innovations reveal that offering worldclass quality is not inconsistent with reducing costs.

The U.S. health sector, however, may soon resemble other innovation-intensive industries in one important respect: it may find its industry leaders displaced by Indian offerings. If dramatic cost differences persist between procedures performed in Indian and U.S. hospitals, it might not be long before employers and insurers begin sending patients to India for treatment. Even with regulatory barriers that weaken innovative entrants, U.S. providers and policymakers may realize that those barriers only extend up to America's borders and offer no protection from the market forces exerting themselves beyond.

The authors did not report any financial disclosures relevant to the content of the paper. Kevin Schulman has made available a detailed listing of disclosures; it is available online at http://content.healthaffairs.org/cgi/content/full/ 27/5/1260/DCl. The authors thank Damon Seils for invaluable editorial assistance.

\section{NOTES}

1. A photo is available online at http://content.healthaffairs.org/cgi/content/full/27/5/1260/DCl.

2. T. Khanna, V.K. Rangan, and M. Manocaran, "Narayana Hrudayalaya Heart Hospital: Cardiac Care for the Poor," Harvard Business School Case Study no. 9-505-078 (Boston: HBS, April 2006); and World Bank, "Health Expenditures, Services, and Use," in World Development Indicators (Washington: World Bank, 2008), Table 2.15 (2005 data).

3. C.M. Christensen, The Innovator's Dilemma: When New Technologies Cause Great Firms to Fail (Cambridge, Mass.: Harvard Business School Press, 1997); and C.M. Christensen, R. Bohmer, and J. Kenagy, "Will Disruptive Innovations Cure Health Care?" Harvard Business Review 78, no. 5 (2000): 102-117.

4. R. Henderson and K.B. Clark, "Architectural Innovation: The Reconfiguration of Existing Product Technologies and Failures of Established Firms," Administrative Science Quarterly 35, no. 1 (1990): 9-30; and C.M. Christensen and R. Rosenbloom, "Explaining the Attacker's Advantage: Technological Paradigms, Organisational Dynamics, and the Value Network," Research Policy 24, no. 2 (1995): 233-257.

5. M.L. Tushman and C.A. O'Reilly, "Ambidextrous Organizations: Managing Evolutionary and Revolutionary Change," California Management Review 38, no. 4 (1996): 8-30.

6. World Health Organization, "Core Health Indicators," http://www.who.int/whosis/database/core/core select_process.cfm (accessed 5 June 2008).

7. S. Sengupta, "Royal Care for Some of India's Patients, Neglect for Others," New York Times, 1 June 2008; and A. De Costa and V. Diwan, "Where Is the Public Health Sector?' Public and Private Sector Healthcare Provision in Madhya Pradesh, India," Health Policy 84, no. 2-3 (2007): 269-276.

8. The high quality at Indian surgical hospitals has already been favorably compared to that in U.S. hospitals. A. Milstein and M. Smith, "Will the Surgical World Become Flat?" Health Affairs 26, no. 1 (2007): 137-141. Fortis and Care hospitals have earned similar recognition. Escorts Heart Institute has a self-reported success rate of cardiac procedures of 99.6 percent and an infection rate of less than 0.3 percent. See "Medical Highlights" on the Escorts home page, http://www.ehirc.com/international_patients/ index.asp. Fortis hospitals have also received Joint Commission International accreditation. See "Fortis Hospital Mohali Gets JCI Accreditation," Press Release, 27 August 2007, http://www.fortishealthcare.com/about_fortis/ 
news_events/fortis_hospital_mohali_js.html (accessed 23 June 2008). Similarly, Care has facilities that are ISO 9001:2000 certified. See "Care Hospital Nagpur Bags ISO 9001:2000 Certification," http://www .carehospitals.com/nagpur/nagpur_iso\%209001_2000\%20certification.htm (accessed 23 June 2008). Also see A. Comarow, "Under the Knife in Bangalore," U.S. News and World Report, 12 May 2008; and Sengupta, "Royal Care."

9. Khanna et al., "Narayana Hrudayalaya Heart Hospital."

10. As evidence of the potential for cost reductions secondary to self-manufacturing capabilities, leaders of the Care Group described a drastic reduction in coil stent pricing upon introduction of their Kamal-Raju coil stent, India's first indigenous coronary stent. Krishna Reddy, chairman of Relisys, estimates that Relisys can reduce the cost of both stents and catheters by 40-70 percent.

11. The lack of an engineering focus in U.S. hospitals has been lamented by experts and is only recently receiving scholarly attention. See "Engineering a Learning Healthcare System: A Look at the Future" (A Learning Healthcare System Workshop, IOM Roundtable on Evidence-Based Medicine, 29-30 April 2008, Washington, D.C.), http://www.iom.edu/cms/28312/rt-ebm/52747.aspx (accessed 5 June 2008).

12. J.K. Iglehart, "The Emergence of Physician-Owned Specialty Hospitals," New England Journal of Medicine 352, no. 1 (2005): 78-84, reports that the number of specialty hospitals grew 20.3 percent annually from 1997 through 2003.

13. Ibid. This idea of specialization as a source of efficiency has been touted as part of a larger U.S. consumerdriven health care movement that aims for wholesale reform. See R.E. Herzlinger, Consumer-Driven Health Care: Implications for Providers, Payers, and Policymakers (San Francisco: Jossey-Bass, 2004).

14. Medicare Payment Advisory Commission, Report to the Congress: Physician-Owned Specialty Hospitals (Washington: MedPAC, 2005), 1-94. Note, however, that developing meaningful measures of quality under these circumstances is difficult. Many of these hospitals served small numbers of patients where measuring outcomes is challenging. See S.M. O'Brien et al., "Exploring the Behavior of Hospital Composite Performance Measures: An Example from Coronary Artery Bypass Surgery," Circulation 116, no. 25 (2007): 2969-2975. Given the difficulty that the federal government had in documenting these outcomes, it is clear that patients would have had a difficult time determining whether these providers were offering superior care.

15. MedPAC, Physician-Owned Specialty Hospitals, 11, 32-35.

16. Ibid.; and Centers for Medicare and Medicaid Services, Final Report to the Congress and Strategic and Implement ing Plan Required under Section 5006 of the Deficit Reduction Act of 2005 (Baltimore: CMS, 2006), 63-66.

17. See CMS, Final Report. The report exhaustively documents the regulatory review and oversight of modest changes in proposed structure of the delivery system. HHS has proposed a broad revision of the DRG system to reduce the overpayment for profitable conditions and to propose moving to a standardized or hospital-specific reimbursement system, neither of which would provide for easy entry of new business models into the market.

18. For the persistence of hospitals negotiating a single price formula for a cluster of services, see C.P. Tompkins, S.H. Altman, and E. Eilat, "The Precarious Pricing System for Hospital Services," Health Affairs 25, no. 1 (2006): 45-56.

19. For an elaboration of the troubling allocative and distributive consequences when provider market power is combined with U.S.-style health insurance, see C.C. Havighurst and B.D. Richman, "Distributive Injustice(s) in American Health Care," Law and Contemporary Problems 69, no. 4 (2006): 14-20.

20. The moratorium was included as part of MMA (PL 108-173, 117 Stat. 2066), which was extended under the Deficit Reduction Act of 2005 (PL 109-171, 120 Stat. 4). See also Iglehart, "Emergence of Physician-Owned Specialty Hospitals."

21. Another regulatory device that enables incumbent hospitals to block potential competitors is certificateof-need (CON) regulations, which still operate in approximately half of the states. For a current and typical CON dispute between competing entrenched interests, see R. Craver, "Mediation Will Start on New Hospital Plans," Winston-Salem Journal, 25 March 2008.

22. C.C. Havighurst, J.F. Blumstein, and T.A. Brennan, Health Care Law and Policy, 2 d ed. (New York: Foundation Press, 1998), 992-1087.

23. For example, see Helling v. Carey, 83 Wash.2d 514 (1974), holding that the reasonable-prudence standard may require a standard of care higher than that exercised by the relevant professional group; and Shilkret v. Annapolis Emergency Hospital Association, 276 Md. 187 (1975), discarding locality rules that permit local deviation from general standards, instead instituting national professional standards for health care providers. 